\title{
Sensory Arts-Based Storytelling as Critical Reflection: Tales From an Online Graduate Social Work Classroom
}

\author{
Alison Grittner and The Social Justice Learning Collaborative
}

\begin{abstract}
Drawing upon Heron and Reason's (1997) participatory inquiry paradigm and extended epistemology, this article explores how six Master of Social Work (MSW) students engaged in sensory arts-based critical reflection concerning their social location, identities, social justice, and social policy. We share our process for creating sensory arts-based stories, the stories themselves, and pedagogical reflections. We elucidate how sensory arts-based storytelling allows learners to draw upon their strengths, unique perspectives, and experiences in the world, generating transformative understandings of social justice. Sensory arts-based storytelling holds potential as an interdisciplinary mode of critical reflection, generating inclusive learning environments oriented towards social change.

In this article, we explore how six Master of Social Work (MSW) Students in an online learning environment engaged in sensory arts-based critical reflection concerning their social location, identities, social justice, and social policy. We share the assignment process, sensory stories, and our reflections on the assignment compared to traditional written forms of critical reflection. Ultimately, we demonstrate how critical reflection pursued through sensory art develops complex understandings of personal identity and social justice in both its creators and audiences. Sensory arts-based storytelling offers a potent interdisciplinary means of cultivating empathetic understandings of power, privilege, and justice, as learners and educators collaborate to disrupt the growing global inequity.

We begin by exploring critical reflection in social work, highlighting this disciplinary practice and its potential for interdisciplinary adoption. We then explore sensory arts-based modalities and situate their potential within critical reflection practice. We follow this with sharing six multimedia arts-based stories created by the MSW students on their identity, social justice, and social policy. Finally, we finish by discussing potentials for integrating these types of assignments into learning environments across disciplines, as well as possibilities for social work practice.
\end{abstract}

\section{Our Location}

We possess multidimensional identities and lived experiences as a learning community. Educated as a historian, visual artist, and architect, Alison led the class and is currently a PhD candidate and social work instructor. She has engaged in arts and community-based research for over a decade, with her current research focusing on engaging communities in participatory and sensory arts-based modalities to understand and cultivate social justice (Grittner, 2019; Grittner \& Burns, 2020). Alyssa, Janelle, Jena, Jeremy, Sarah, and Veronica came to their MSW program possessing varied backgrounds in Law, 
Criminal Justice, Sociology, Physical Education, and Development Studies. No one had previous postsecondary experience in Fine Arts. We came together as a group in their first semester of a two-year foundational MSW program, open to learners without a prior academic social work background, although admission to the program requires extensive experience in the human services. We offer our sensory and arts-based stories as an avenue of possibility for deep critical reflection, connecting identity and embodied experience with social justice.

\section{Extended Epistemology Theory}

We locate sensory arts-based storytelling within Heron and Reason's (1997) participatory inquiry paradigm and extended epistemology, which proposes that, "experiential encounter with the presence of the world is the ground of our being and knowing" (p. 276). Within this perspective our social positions and lived experience create our worldview. Heron and Reason suggest that an individual "articulates a world" (p. 280) via four interwoven means: experiential, presentational, propositional, and practical knowing. Experiential knowledge is created through direct encounter with a feeling, an imaginative vision, or a specific person, place, or artefact. Experiential knowing generates presentational knowledge, conceived of as multimodal art that symbolizes a person's "felt attunement" (p. 281) with their world and experiences. Propositional knowledge describes and conceptualizes our experiential knowing through theory, language, and text and can also be embodied, reflected, and cultivated through presentational knowing. Practical knowing amalgamates and generates action from experiential, presentational, and propositional knowledge, and is a political act "in practical service to people's lives" (p. 288).

Understanding that knowing emerges from these four different but iterative and interconnected modalities, we explore how experiential (sensory) and presentational (arts) knowing offer a revelatory critical reflection process that moves beyond the academy's widespread rootedness in propositional knowing. This expansion is a place of struggle and tension across academia, which "often disadvantages, marginalizes, or excludes knowledges from other places and perspectives" (Massaquoi, 2017, p. 295). We position sensory arts-based storytelling as one strategy for broadening knowledge creation to include experiential and presentational ways of knowing, asserting that experience and creativity are bases of knowledge. This expansion recognizes multiplicity and difference within classrooms by offering multiple approaches for learners to explore their diverse strengths, experiences, and ways of knowing.

\section{Social Work and Critical Reflection}

The critical use of self, positionality, and reflection within research, theory, and practice are foundational to social work (Brookfield, 2009; Heron, 2005). Critical reflection begins by understanding that all knowledge and action is political. Reflection unravels how our identities, beliefs, and experiences influence our understanding and behaviour in the world. Heron and Reason (1997) term this, "critical subjectivity," whereby persons strive to define and understand "the ground of all [their] 
knowing" (p. 282). This begins with all social work students exploring their social location, relationship with knowledge, motivations for practice, and connection with the world.

Critical subjectivity is embedded in critical reflection, which Brookfield (2016) defines as: "the uncovering of power and hegemony... [demonstrating] how ideological manipulation forces us to behave in ways that seem to make sense, but that actually keep us powerless" (p. 1). Together, critical subjectivity and critical reflection prompt social workers to critically interrogate our own beliefs and assumptions concerning our identities, social locations, and cultural context as a key first step towards pursuing social justice. A core component of competent social work practice, and thus social work pedagogy, is understanding our own social positions and how we experience intersections of oppression and privilege (Morley et al., 2017). Critical practitioners continually analyze power differentials, asking how beliefs, assumptions, social location, and embodied experiences affect our reflexive relationship with the world (Etherington, 2007).

While critical reflection is a core disciplinary practice of social work, it is also a focus of critical pedagogy, which posits that educational processes can advance social justice. Education is conceived of as a praxis involving theory, action, and reflection with the overall goal of liberation (Breuing, 2011). Consciousness raising is central to critical pedagogy, in which learners explore the existence and role of oppression, socio-structural power, and strategies for social transformation (Weiler, 2001).

We propose that sensory arts-based storytelling is a critical reflection modality that can be used across disciplines interested in generating inclusive and critical learning environments. The importance of this as a cross-disciplinary practice is highlighted in the ever-widening gaps in global inequity, sharply illuminated during the present COVID-19 global pandemic, the Black Lives Matter and MeToo movements, and Canada's ongoing violence against Indigenous persons. Understanding hierarchies of difference and countering processes of oppression become more important every day. We believe that sensory arts-based storytelling is one means of answering Guattari's (2005) call to action of "[warding] off, by every means possible, the entropic rise of a dominant subjectivity," and embracing "new social and aesthetic practices, new practices of the Self in relation to the other, to the foreign, the strange" (p. 68) as a strategy of resistance against dominant modes of knowledge creation and power.

\section{Sensory Arts-Based Storytelling}

Sensory arts-based storytelling uses arts-based (drawing, photography, music, movement, performance, new media) creations to understand, explore, and share multidimensional stories of being in the world. Sensory storytelling challenges traditional Eurocentric approaches to knowledge that privilege the ocular, words, and text, by emphasizing "dynamic interactions among sounds, tastes, odors, touches, senses of place and of belonging and exclusion" (Culhane, 2016, p. 11).

Sensory practice views the division of the senses as a Western construct (Pink, 2011; Howes, 2019). Instead, all senses are understood to be part of the sensorium, which highlights the shifting boundaries and different combinations of the senses across cultures and groups (Howes, 2019). Sensing involves 
whole body perception; aural and visual stories evoke different aspects of the senses within a holistic multisensory system, emplacing audiences in the sensory story (Pink, 2015). Individuals are understood to be sensing subjects situated within specific cultural and environmental contexts (Howes, 2019). Scholarship is increasingly demonstrating the sensory nature of our life-worlds and identities (Culhane, 2016), and sensory storytelling is a growing tool to share embodied experiences of the world, understanding that, "culture does not reside only in objects in representations, but also in the bodily processes of perception" (Csordas, 1999, p. 146).

Pink (2015) observes that sensory creations facilitate an embodied and active role for their makers and audiences, offering contemplative and reflexive processes for empowered learning. Creative sensory modalities allow learners to consider and reflect their knowledge and experiences in the world in a manner more closely aligned with how we experience life: embodied and sensorially immersed (Pink, 2015). As sensory practices are also related to power-Howes (2016) writes that "sensory critique is the beginning of social critique" (n.p.) as the senses are intermixed with experiences of classism, ideology, and inequitable distribution of resources and opportunity-attending to the senses is one avenue for explicating social justice.

One means of uncovering and exploring sensory experiences is through arts-based methods: creating visual, aural, and kinesthetic records is a holistic bodily process involving the entire sensory system. Sensory arts-based storytelling is a situated practice within arts-based methods that embed critical reflection in the creation process, generating an artifact that communicates knowledge visually, symbolically, and imaginatively (Wang et al., 2017). Dissanayake (1988) observes that the arts represent "embodiment and reinforcement of socially shared significances" (p. 200). Definitions of arts-based practice recognize it as creating meaning "through multiple senses and medium" (Desyllas, 2014, p. 478), while exploring, understanding, representing, and challenging our lived experiences and views of the world (Baden \& Wimpenny, 2014). To draw and create visually based art involves being rooted in the environment with concentration, positioning our bodies to sense, translating the surrounding context through our bodies onto paper and canvas (Taussig, 2011). Drawing, painting, mapping, and collage are acts of sensory transmission, interpretation, and creation: the body is an intermediary between experience and record. Creators engage their senses while expressing emotions and cognitive processes during artmaking (Hass-Cohen, 2008; Mallay, 2002). Creating sensory art-based stories connects embodied experience to the external world, linking externalities with more abstract dimensions of experience including emotions, memories, and senses (Cele, 2006). Artmaking provides learners opportunities to reflect and express their interior emotional world and relational experiences, generating new ways of seeing themselves and their environments (Capous-Desyllas \& Bromfield, 2020).

Arts-based practices explore the substance and relationship between power, dominance, and oppression (Sinding et al., 2014; Sitter et al., 2016). Leonard and colleagues' (2018) systematic review of the arts in social work education found that arts-based approaches effectively fostered connections between micro and macro practice among learners. Through the arts, students integrated learning of how individual experiences are connected to socio-structural issues of power. Further, arts-based modalities were identified as having three benefits: 1) expressing "socially messy, problematic emotions and experiences" 
(p. 12); 2) generating empathy concerning difference; and 3) confronting hegemonic beliefs of the world (Leonard et al., 2016). Thus, telling stories in artful ways holds a pathway to transformation. As Kovach (2018) observes: "story is experience held in memory and story is the spark for a transformative possibility in the moment of its telling" (p. 46).

Creating a sensory arts-based story allows deeper understanding of our own socially contextualized experience, while witnessing another's story deepens our empathetic understandings of our shared world. This process of telling and listening is particularly transformative when the stories involve voices of marginalized identities challenging dominant narratives: "to counter oppression, stories must be told, listened to, and acted upon" (Zusman, 2018, p. 80). Sensory arts-based storytelling in the classroom allows learners to draw upon their strengths, unique perspectives, and experiences in the world to generate deep critical reflection surrounding social justice, reminding us that we are all political actors (Alexander-Floyd, 2012).

\section{Educational Context}

This sensory arts-based assignment was completed as part of a graduate course titled, "Social Policy and Social Justice." At the last minute, this course was delivered online due to the COVID-19 pandemic; the assignment was designed to provide students space for critical reflection and learning away from their computer screen. The course took place within the compressed structure of four full-time weeks with 32 enrolled students.

At their end of their first week of class, students created sensory essays that critically reflected on their relationship to social justice and social policy. Key learning outcomes associated with the assignment involved: understanding theory in relationship to social justice; demonstrate understanding of the roles that ideologies, values, and worldviews play in relationship to social justice; demonstrate critical thinking and reasoning in analyzing complex social situations; and apply critical thinking to identify and address structural sources of injustice and inequalities. Students were encouraged to use experiential and presentational knowledge to develop their awareness of identity and embodied experience, then connect these ways of knowing to social and cultural contexts, spurring critical reflection. As the first assignment in the course, it created the foundational understanding necessary for learners to analyze social policy and make recommendations for policy change rooted in social justice and critical reflection. Figure 1 is the assignment instructions, collaboratively revised by all the authors to enhance future learner experience. The assignment instructions are deliberately open and fluid, seeking to not limit creativity, exploration, and learner agency, as well as encouraging heuristic learning. As the instructor, Alison responded "Yes!" to any learner proposed variations, ideas, or formats. 


\section{sensory Ats-BasedEsal}

Sensory arts-based essays are multi-modal storytelling that include impressions, imagery, memory depictions, music, drawings, smell maps, symbols, soundscapes, spoken word, tactile landscapes, etc. to explore a topic, answer a question, and tell a story. Ahmed (2017) observes that understanding the social world, social justice, and our social location is a messy, sweaty, and complex endeavour; sensory essays offer a creative and reflective means of analyzing these complexities and embodied experiences.

For this assignment you will compose a sensory essay that critically reflects upon your relationship with social justice. In other words: How does social justice intersect with your everyday life? How do you experience socio-structural power (ex: colonialism, racism, sexism, ableism, classism, etc.) in your everyday environments?

Guiding questions to consider/kick-off your exploration:

- What messages do you experience in your everyday life surrounding social justice? In what form are these messages?

How does your body respond to these messages? Remember, absence and invisibility are also responses.

- What bodily experiences (sights/smells/sounds/touches/tastes/feelings) come to mind when you think about socio-

structural power and your everyday life?

- What does social justice feel like in your body?

- How are aspects of your social location symbolized and embedded in your everyday environment? How are these

aspects sensorily communicated and experienced within your body?

- What would you include in a self-portrait to communicate your social location?

- What bodily experiences (sights/smells/sounds/touches/tastes/feelings) in your home/neighbourhood/city communicate your social location?

Your sensory essay can consist of the following two components:

- 3-5 visuals (photography, art, collage, texturescapes, smellmaps, symbols, or other forms of imagery)

- Narrative that connects, reflects, and tells a story in relationship to your images ( 300 words maximum, spoken/sung,

and recorded. Soundscapes or music can also be used as narrative.)

Note: You are welcome to expand your sensory composition beyond static imagery. The audio-visual format described

above is a suggestion and creative sensory exploration is encouraged.

Suggested Plan for Creating:

1. Identify the topic and the theme of your sensory essay. The sensory essay should develop a personal narrative of some aspect of your relationship to social justice and/or social policy and your social location.

2. Ideate, brainstorm, and plan. Bring your ideas to our collaborative pitch-and-charette session where we'll discuss and speculate together

3. Select/Create $3-5$ visuals to include in your sensory essay. Storyboarding these can be helpful.

4. Craft an audio narrative that complements and expands your storytelling. The way in which you construct your experience is up to you, but you need to consider why you are choosing particular mode(s) of composition to reflect on your experiences.

5. Select a technical application to create your essay. Combining sound and images in PowerPoint is relatively simple. For those with Mac products, iMovie is another easy to use application for composing audio-visual media. Youtube contains free tutorials for both pieces of software as well as others.

6. Submit your completed composition on our community discussion board. Sharing your embodied experiences is a means of community building within our community, even though we're all currently physically separate during the pandemic.

Fig. 1: Sensory arts-based essay assignment instructions

We are excited to share five sensory arts-based stories created by Alyssa, Janelle, Jena, Jeremy, Sarah, and Veronica. Each story weaves together visuals, sounds, and narrative in an immersive video format that embodies critical reflection surrounding their identity, lived experience, social justice, and social policy. Following each creator's video is an accompanying textual statement written four months after completing the course. These statements explore their creative experiences, providing direct experiential insight concerning how sensory art-based knowing can enhance dominant forms of propositional knowing within critical reflection processes. 


\section{Adventures in Sensory Art}

\section{Alyssa}

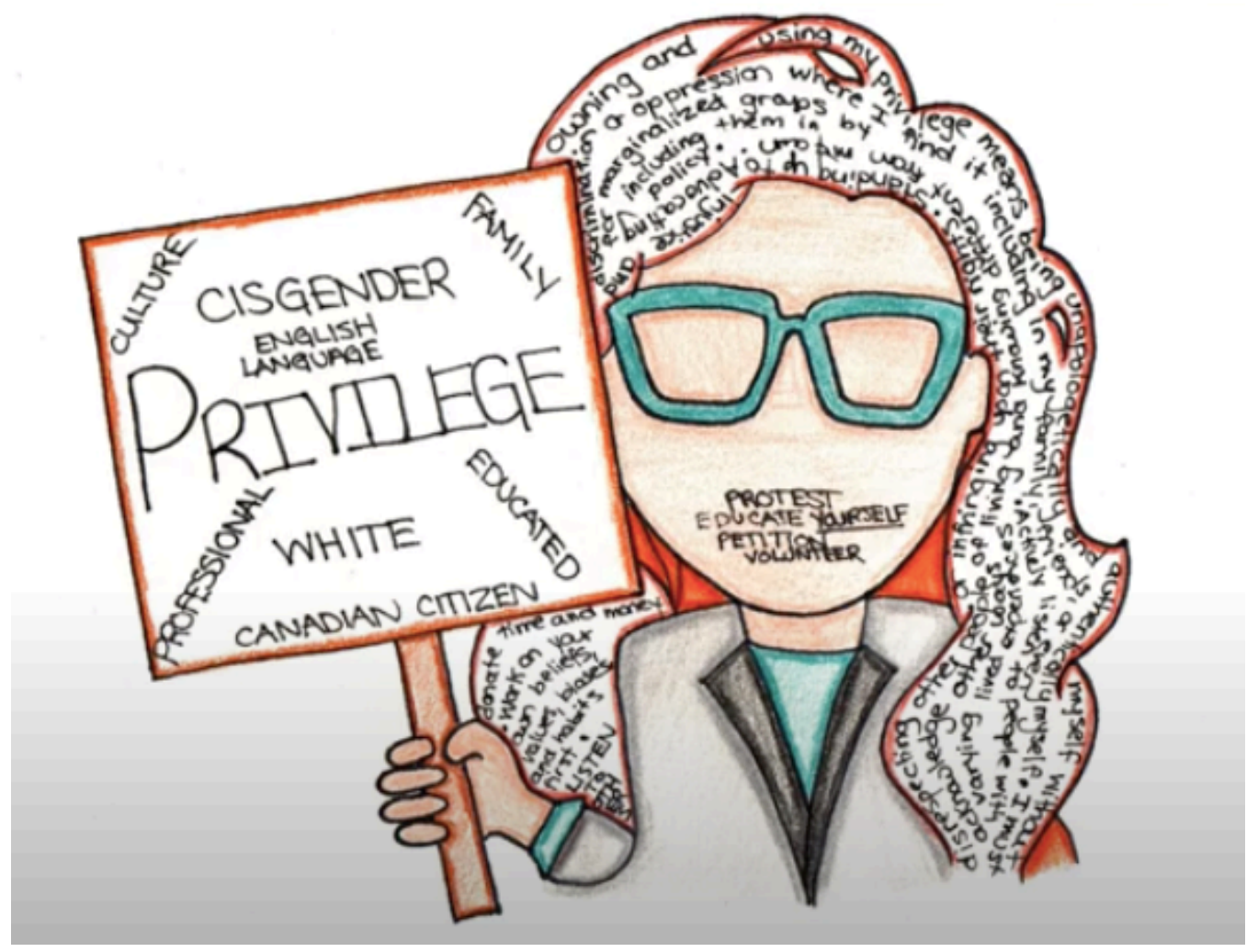

https://youtu.be/aiKfG48VrOQ

When I first heard that we were doing an academic assignment formatted as a creative art project, I was beyond nervous. My previous six years in academia were centered around exams and essays. I was not sure I even had the ability to create something anymore. However, I quickly came to realize that not only was I more engaged with this assignment than any previous essay or exam, but I evaluated the topic and integrated it more fully into my thought process and daily life. I was able to thoroughly examine my social location, how others perceive me, and the ways in which my experiences could contribute to positive social action and social justice. 


\section{Janelle}

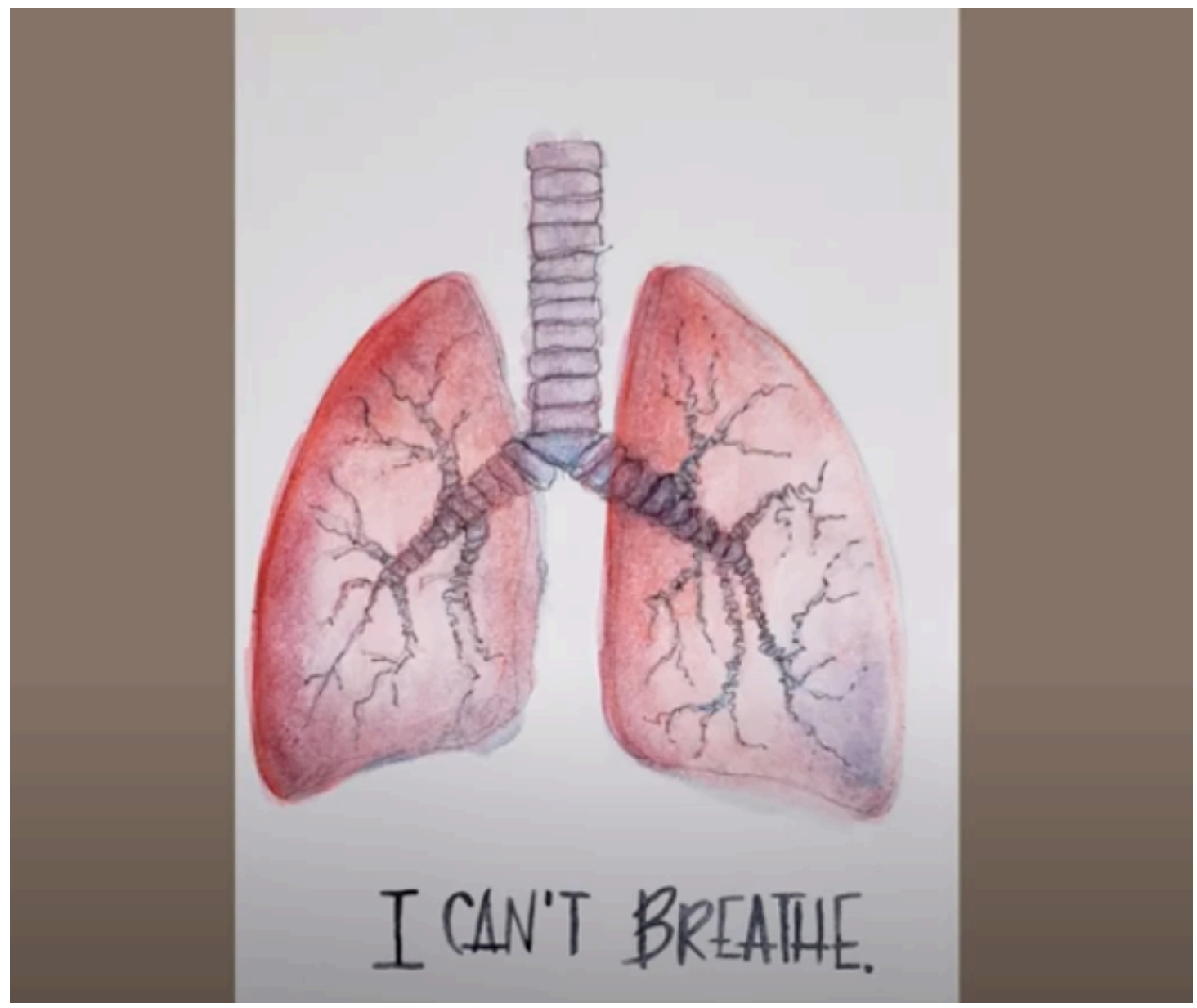

https://youtu.be/XvDrQnqIPQA

This sensory essay was very exciting for me, and novel in its combination of creative arts and school project. It was both humbling and confronting, it provided space for introspection pertaining specifically to future work. The social climate under the Black Lives Matter movement with the privilege of education during a pandemic meant that the project was a timely and welcome form of documentation. Visually recording moments of my life removed any concessions or distractions from presenting my social location, as the pictures invite the viewer to see things exactly as I do, with my exact interpretation of those moments. 
Jena

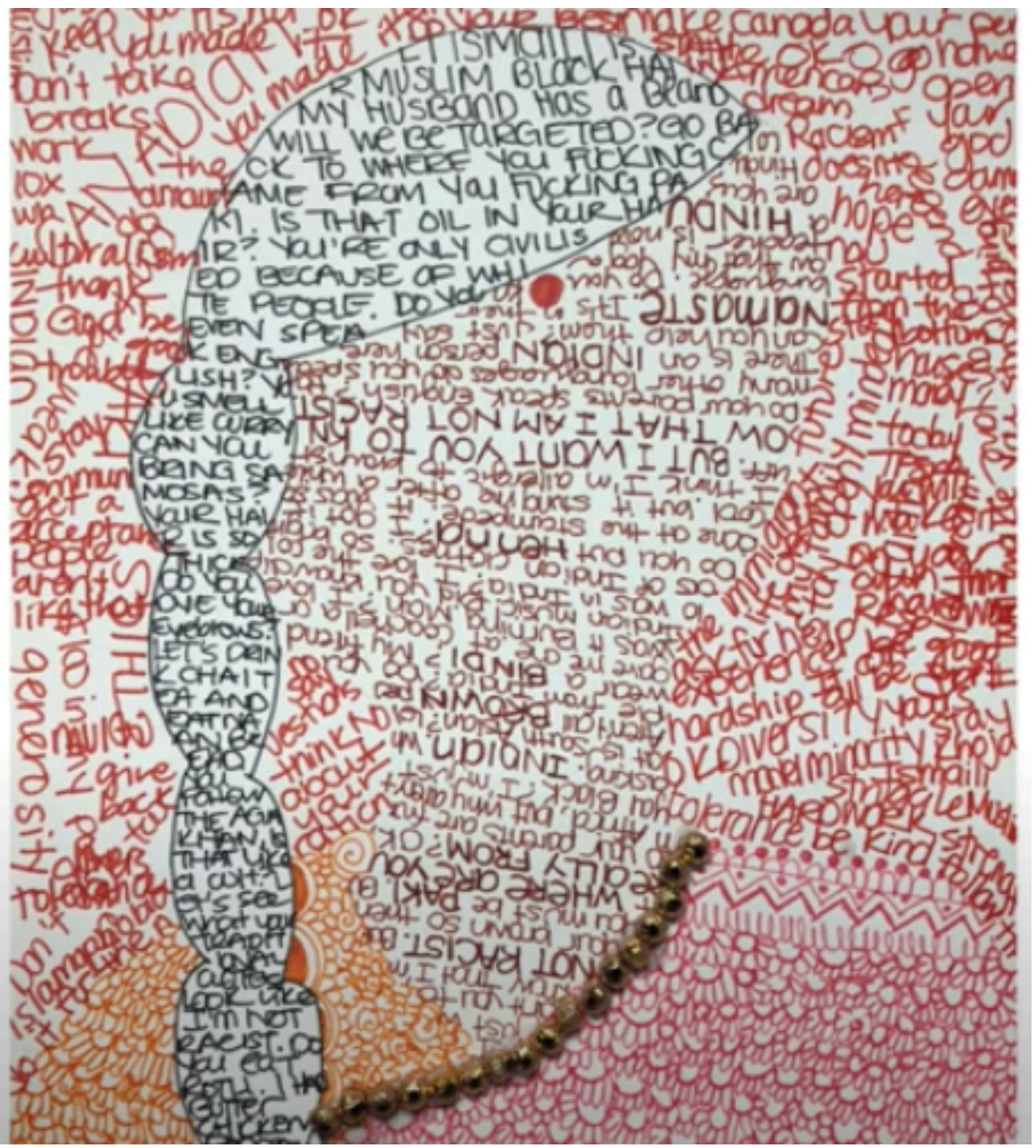

https://youtu.be/EpKAYGSF_FQ

The sensory essay assignment was really unique and different from a traditional assignment, as I was able to add parts of my identity. Through my assignment I was able to be creative and explore aspects of my culture that I cannot type into a Word document. The visual and artistic aspect forced me to think about my South Asian heritage differently, and how I wanted to demonstrate my social location to my class, visually. I have never been challenged in academia this way and it was a therapeutic activity that made me feel that my identity as a child of immigrants is valued in my educational experience. 


\section{Jeremy}

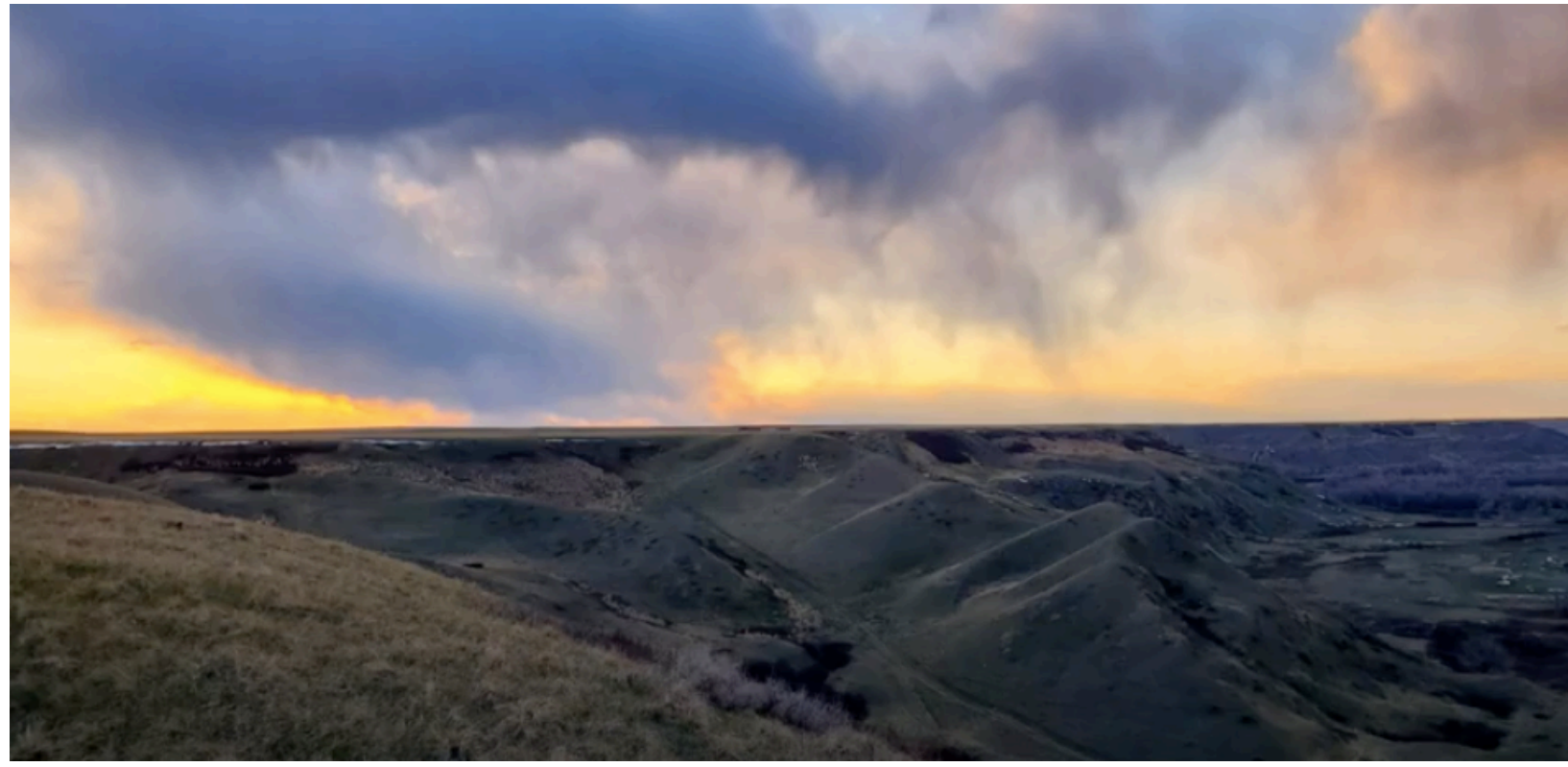

https://youtu.be/-pNqVp5XLao

When I first read the "Sensory Essay" requirements I was filled with anxiety for not having done one before, but then filled with embarrassment and fear. This embarrassment and fear stemmed from the details of the assignment that involved exploring my social location, applying concepts of social justice and social policy in connection to my personal identity. I immediately thought of my home growing up, and reasons why we had to leave. I began to think: what would my Professor, my cohort, and my family think of the pictures? I was conflicted, thinking of my social location and my willingness to share it. The more I thought about my social location, the more I realized that it was an Indigenous social justice issue that just didn't affect me, but Indigenous people across Canada, resulting from oppressive policies like the Indian Act.

My Indigenous social location, along with many Indigenous people in Canada, includes racism, discrimination, oppression, and hegemony. I realize now that the conflict I had in my willingness to share my social location stemmed from my internalized racism. I look at the picture of my home and remember the times as a kid spent watching 500 Nations, along with having many conversations with my father and mother, watching movies and documentaries that all helped me gain an understanding of my culture and gain a sense of pride in who I was. Becoming more reflective throughout my studies in the Calgary MSW program, I am becoming more aware of the importance and the need to tell my story as an Indigenous person.

The sensory essay allowed me to do so. 


\section{Sarah}

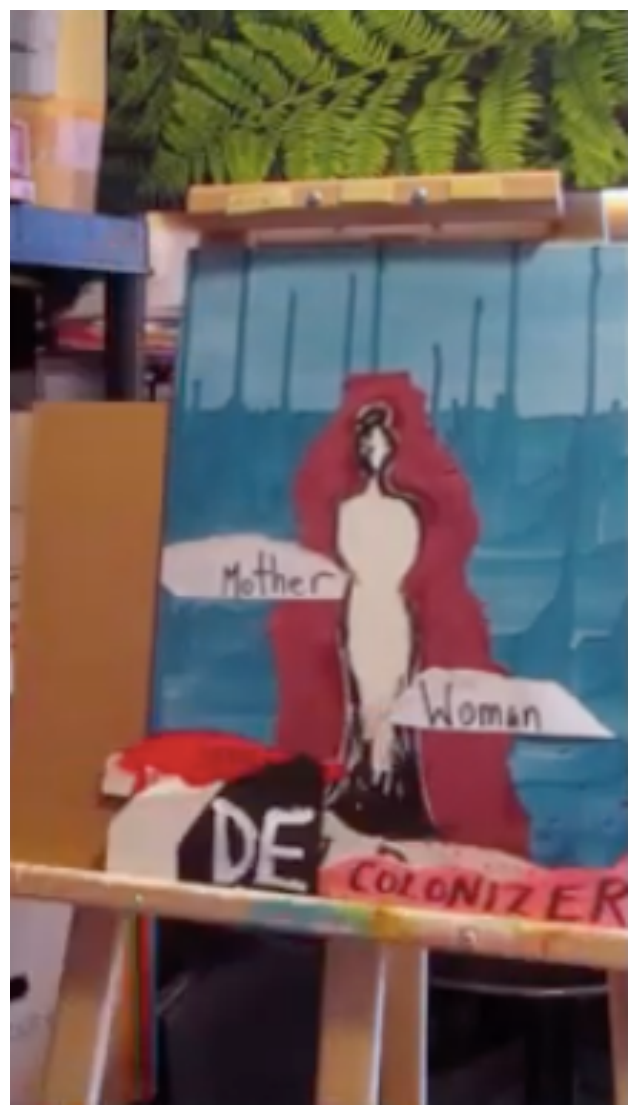

https://youtu.be/dR7RPhfjP7k

I had never done a sensory essay before, but with all the online learning, it was a welcome opportunity to unplug. The challenge was starting. I spent a day exploring different ideas and felt like I was getting nowhere. Finally, I just had to start. I had some rough ideas and decided I would start by drawing me: a generic sort of image that would also represent all women. I did not know what would unfold as I began, but I knew to trust the process and give in to the flow. I immediately struggled, for one or two hours even, on drawing a female body that felt 'right.' I was forced to reckon in a new way with how political our bodies are. I was frustrated and angry with the process that had barely begun, saying to myself: "I can't even draw a woman's body! What does that say about being a woman in this world?" I think this offered the entry point and allowed me to get lost in the process and I started to go with whatever came up.

What became apparent to me through doing this sensory essay, is of the multitude of dimensions or layers to learning, one of them seems to be time. When I think of the time it takes to truly integrate social justice learnings so that it becomes not just intellectual knowledge but 
felt and lived understanding, it seems like a lifelong project. After just a weekend of working on this project, I felt different. This sensory story helped me to integrate course content, but more importantly, it helped me become a better human. That piece will forever be a part of me and it's much more impactful to look at on my wall than any paper.

\section{Veronica}

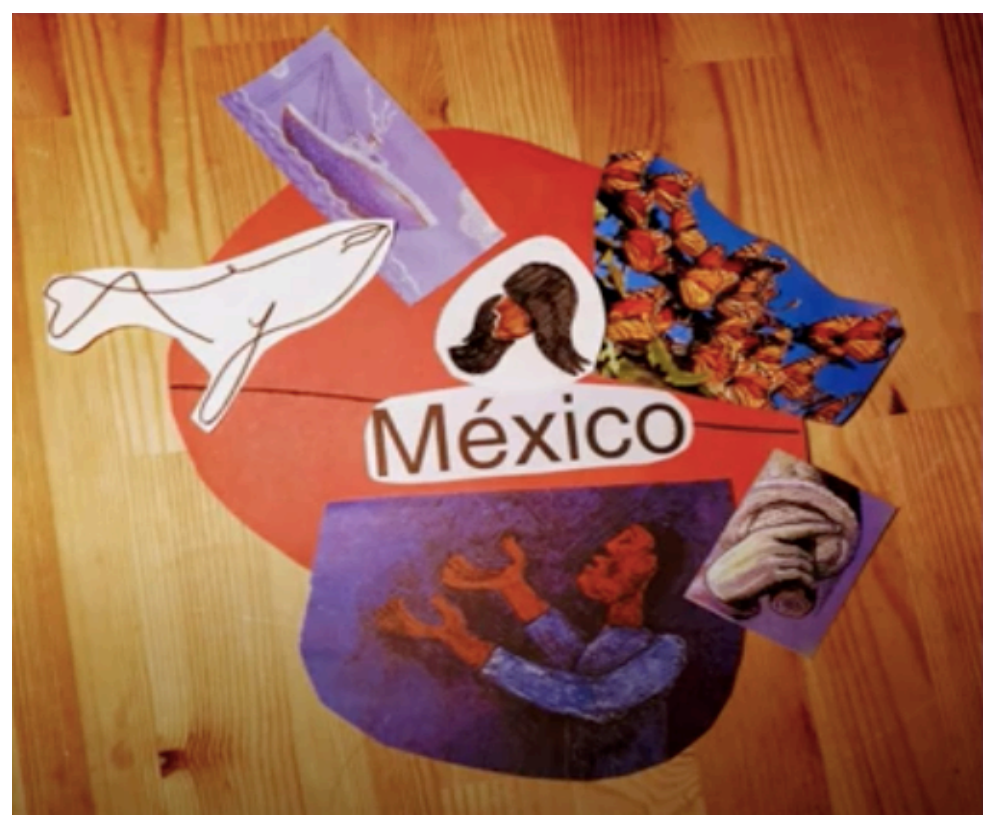

https://youtu.be/6QEjwPEF5NE

When I heard about having a "sensory project" I had mixed emotions. I was nervous and excited at the same time. During the activity, I became aware of my social location. I am originally from Mexico. I am part of a multicultural family and I was not mindful of the privileges I received and challenges I faced. In Mexico, I was not fully aware of the injustices that we were/are still experiencing due to colonialism and a patriarchal society. Sometimes in a world with oppression, it is easier not to look at the unfairness, the injustices. Through this assignment I saw my life like different pieces of a puzzle that led me to social work and social justice advocacy.

\section{Alison}

As a social work educator, I read hundreds of traditional text-based critical reflections every year. Comparatively, the sensory and arts-based stories from this class embodied far greater complexity and depth of critical thinking, particularly concerning social location and identity. My affective viewing experience lingered: watching the stories sensorily emplaced me, allowing me to "empathetically imagine" (Pink, 2011, p. 9) the learners' experiences. 
Months after the course finished, I kept revisiting these pieces of art, my own life transformed, and perspective expanded through these stories. I returned to Alyssa's position of the space in between as the ongoing pandemic emphasized ableist discourse surrounding comorbidities and age. Janelle's story of confronting racism while holding educational and class privilege echoed within me while I marched in Black Lives Matters demonstrations. Jena's experiences of the colonial gaze returned each time I ordered chai in a café, prompting me to examine my complicity in corporate and cultural colonization. Camping and hiking in the Alberta prairies I recalled Jeremy and his family's disrupted connection to land and ruminated on my power and position within settler-colonialism. Sarah's expressive painting performance returned to remind me of the complexity of gendered experiences in patriarchal waters as I listened to friends' struggles with childcare and the COVID-19 "she-cession." The very personal connections Veronica drew to Mexican foreign temporary workers resurfaced as I became increasingly aware of Canada's exploitation of foreign labour and the ideological underpinnings within Canadian politics that allows this practice. I considered revolution. Learning with Alyssa, Janelle, Jena, Jeremy, Sarah, and Veronica through sensory arts-based storytelling was a powerful experience of Freire's (1970) process of "conscientization": my everyday awareness of differences of power and privilege increased, as did my commitment to social justice advocacy and education.

\section{Discussion}

\section{Sensory Arts-Based Storytelling in the Classroom}

Opportunities abound for sensory arts-based storytelling as a form of critical reflection in the classroom. This creative medium allows learners to incorporate additional modalities within their stories, including performance art (e.g., dance, music, or theatre) (Hamera et al., 2011) or soundscapes, which record ambient noises of places and experiences (Droumeva, 2015). The growing ubiquity of smartphone technology for audiovisual recording, as well as access to editing software, broadens opportunities to incorporate these approaches within online environments. Increasing digitalization of our world is improving academia's potential to engage in socially relevant and popular means of communication and dissemination (El Demellawy et al., 2017). When designing the assignment, Alison was concerned that learners might spend excessive time struggling with technology as they composed their pieces. However, as a group, they produced much more nuanced and complex compositions than the assignment required: unprompted, most students chose to combine multiple modes of sensory expression and art.

The complex and nuanced level of these pieces of sensory art does not mean that the creative process did not provoke anxiety. As Alyssa, Janelle, Jeremy, Sarah, and Veronica share, the assignment provoked 
bewilderment. A number of educators who examine the how and why of critical reflection within pedagogy term this family of experience as a "felt difficulty" (Ixer, 1999, p. 515) or a "disorienting dilemma" (Brookfield, 2009, p. 295). Brookfield (2009) explains that creating a stark discrepancy between assumption and encounter-in our example, between traditional expectations of what an academic assignment involves vs. processes of experiential and presentational knowing-generates emergent and transformative learning. Through this process "the tacit forms of knowledge that undergird one's habitual responses emerge as assumptions in need of scrutiny" (Trevelyan et al., 2014, p. 13). In creating sensory arts-based stories as a mode of critical reflection, learners are forced to move beyond academic training that emphasizes translating thoughts and experience into academic text, moving towards Tuhiwai Smith's (1999) call to decolonize knowledge processes. Wrestling with new sensory and creative modalities challenges assumptions, beliefs, and knowledge concerning their identities and relationship to the world, instigating intense and complex critical reflection.

Recognizing and embracing the potential uncertainty of this assignment requires building space to discuss hesitations, fears, and expectations into the course. From the beginning, Alison emphasized that the projects would not be graded on artistic representation skills; this was included in the assignment instructions and repeated in class discussions. To address emergent concerns, we scheduled drop-in time for learners to discuss their ideas with both Alison and their colleagues. This additional space for discussion and reassurance that the assignment was about individual process and exploration, as well as providing a forum to discuss creativity and ideas, was essential. A dedicated time to brainstorm these forms of assignments is recommended and will be incorporated into future iterations.

\section{Practice Potentials}

Sensory arts-based stories' promise is not limited to the classroom. They are also a potential tool for critical reflection and social change among social work practitioners and clients. For practitioners, the arts are a means of engaging groups to work towards a collaborative vision (Newton, 2011), a key goal of community development (Parada et al., 2011). Capous-Desyllas and Morgaine (2018) write that a merger of arts-based and anti-oppressive practice is one strategy for challenging hierarchies of domination and generating "creative responses to challenging and changing social contexts" (p. xv) that mobilize imaginations towards social change. Creative exploration of social change is critical, otherwise the "future flattens out into uncritical extrapolations from the present" (Knight, 1981, p. 28). For practitioners, creative explorations both critique the present and offer alternative ways of being, instigating the possibility of social transformation.

Sensory arts-based storytelling is vulnerable, ambiguous, and messy, just like lived experience; this form of storytelling is a nuanced medium to deepen understandings of clients' perspectives. Sensory arts-based stories transcend the limits of language, communicating aspects of experience and meaning that are embodied, visceral, and often befuddling. Scholarship shows that arts-based dialogue can improve understanding of clients' needs. Malchiodi (2018) used art as an explanatory recovery tool with her care team after a traumatic brain injury, while art installations were used to educate social service providers and the general public on the challenges vulnerable individuals experience when attempting to access 
social services in Los Angeles (Reshetnikov et al., 2018). These forms of arts-based storytelling generate social empathy-defined as the ability to understand others' experiences and life situations (Segal, 2011)_among both practitioners and the general public. Segal's scholarship argues that social empathy spurs action towards social justice, as countering misinformation and stereotypes dissolves rationale for inequitable social conditions and catalyzes individuals towards social action. Sensory arts-based stories are an innovative medium to cultivate relationship-building and perspective-sharing, foundations of social empathy and social change. This will also assist in ethical practice, which requires analyzing what perspectives and knowledge are guiding practice decisions by framing social issues and understanding clients' experiences (Strom-Gottfried, 2008).

Creating these sensory pieces of art facilitated deep critical reflection and awareness among the learners of their social location and connection to larger socio-structural issues of power. For Alison, viewing these pieces was a transformative experience that prompted her to reconsider aspects of her own identity and expanded her understanding of our shared cultural context. Together, we share these pieces and our creative learning experience as a prompt towards social transformation, embracing Lorde's (1984) teaching that, "the quality of light by which we scrutinize our lives has direct bearing upon the product which we live, and upon the changes which we hope to bring about though those lives ... carved from the rock experiences of our daily lives" (pp. 36-37).

\section{References}

Alexander-Floyd, N. G. (2012). Disappearing acts: Reclaiming intersectionality in the social sciences in a post—Black feminist era. Feminist Formations, 1-25.

Baden, M. S., \& Wimpenny, K. (2014). A practical guide to arts-related research. Springer.

Breuing, M. (2011). Problematizing critical pedagogy. The International Journal of Critical Pedagogy, 3(3).

Brookfield, S. (2009). The concept of critical reflection: Promises and contradictions. European Journal of Social Work, 12(3), 293-304.

Brookfield, S. (2016). So what exactly is critical about critical reflection? In J. Fook, V. Collington, F. Ross, G. Ruch, and L. West (Eds.). Researching Critical Reflection. Multiple Perspectives (pp. 11-22). Routledge.

Capous-Desyllas, M., \& Bromfield, N. F. (2020). Field note-Exploring the use of arts-informed journaling in social work field seminars. Journal of Social Work Education, 56(1), 201-209.

Capous-Desyllas, M., \& Morgaine, K. (2018). Creating Social Change Through Creativity. Springer.

Cele, S. (2006). Communicating place: methods for understanding children's experience of place (Doctoral dissertation, Acta Universitatis Stockholmiensis).

Csordas, T. (1999). Embodiment and cultural phenomenology. Perspectives on embodiment: The intersections of nature and culture, 143, 162. 
Culhane, D. (2016). Imagining: An Introduction. In D. Culhane and D. Elliott (Eds.), A different kind of ethnography: Imaginative practices and creative methodologies (pp. 1-21). University of Toronto Press.

Desyllas, M. C. (2014). Using photovoice with sex workers: The power of art, agency and resistance. Qualitative Social Work, 13(4), 477-501.

Dissanayake, E. (1988). What is art for? University of Washington Press.

Droumeva, M. (2015). Curating everyday life: Approaches to documenting everyday soundscapes. M/C Journal, 18(4).

El Demellawy, H., Zaman, B., \& Hannes, K. (2017). An exploration of the potential of progressive dissemination formats of research findings. ECQI 2017 PROCEEDINGS, 2017, 208.

Etherington, K. (2007). Ethical research in reflexive relationships. Qualitative inquiry, 13(5), 599-616.

Freire, P. (1970/2000). Pedagogy of the oppressed. Rowman \& Littlefield.

Grittner, A. L. (2019). The Victoria Mxenge: Gendered formalizing housing and community design strategies out of Cape Town, South Africa. Journal of Housing and the Built Environment, 34(2), 599618.

Grittner, A. L., \& Burns, V. F. (2020). Enriching social work research through architectural multisensory methods: Strategies for connecting the built environment and human experience. Qualitative Social Work. https//doi:1473325020924456.

Guattari, F. (2005). The Three Ecologies. Bloomsbury Publishing.

Hamera, J., Denzin, N. K., \& Lincoln, Y. S. (2011). Performance Ethnography. Sage.

Hass-Cohen, N. (2008). Partnering of art therapy and clinical neuroscience. Art therapy and clinical neuroscience, 21-42.

Heron, B. (2005). Self-reflection in critical social work practice: subjectivity and the possibilities of resistance. Reflective practice, 6(3), 341-351.

Heron, J., \& Reason, P. (1997). A participatory inquiry paradigm. Qualitative Inquiry, 3(3), 274-294.

Howes, D. (2016). Sensing cultures: cinema, ethnography and the senses. Beyond Text? Critical. Practices and Sensory Anthropology, 165-180.

Howes, D. (2019). Multisensory anthropology. Annual Review of Anthropology, 48, 17-28.

Ixer, G. (1999). There's no such thing as reflection. The British Journal of Social Work, 29(4), 513-527.

Knight, I. (1981). The feminist scholar and the future of gender. Alternative Futures, 4.2-3, 17-35.

Kovach, M. (2018). A story in the telling. LEARNing Landscapes, 11(2), 49-53.

Leonard, K., Hafford-Letchfield, T., \& Couchman, W. (2018). The impact of the arts in social work education: A systematic review. Qualitative Social Work, 17(2), 286-304.

Lorde, A. (1984). Sister Outsider. Crossing. 
Malchiodi, C. A. (2018). Creative arts therapies and arts-based research. In P. Leavy (Ed.), Handbook of arts-based research, 68-87.

Mallay, J. N. (2002). Art therapy, an effective outreach intervention with traumatized children with suspected acquired brain injury. The Arts in psychotherapy, 29(3), 159-172.

Massaquoi, N. (2017). Crossing boundaries. Radicalizing social work practice and education.

In D. Baines, (Ed.). Doing Anti-oppressive Practice. Social Justice Social Work (3rd ed.) (pp. 289-303).

Fernwood Publishing.

Morley, C., Macfarlane, S., \& Ablett, P. (2017). The neoliberal colonisation of social work education: A critical analysis and practices for resistance. Advances in Social Work and Welfare Education, 19(2), 25-40.

Newton, K. (2011). Arts activism: Praxis in social justice, critical discourse, and radical modes of engagement. Art Therapy, 28(2), 50-56.

Parada, H., Barnoff, L., Moffatt, K., \& Homan, M. S. (2011). Promoting community change: Making it happen in the real world (first Canadian Edition). Nelson Education.

Pink S. (2011). A multisensory approach to visual methods. In Margolis E. \& Pauwels L. (Eds.),The SAGE Handbook of Visual Research Methods (pp. 601-614). Sage Publications.

Pink, S. (2015). Doing sensory ethnography. Sage.

Reshetnikov, A., Bogumil, E., Capous-Desyllas, M., \& Lara, P. (2018). From visual maps to installation art: Visualizing client pathways to social services in Los Angeles. In Creating Social Change Through Creativity (pp. 209-226). Palgrave Macmillan, Cham.

Segal, E. A. (2011). Social empathy: A model built on empathy, contextual understanding, and social responsibility that promotes social justice. Journal of Social Service Research, 37(3), 266-277.

Sinding, C., Warren, R., \& Paton, C. (2014). Social work and the arts: Images at the intersection. Qualitative Social Work, 13(2), 187-202.

Sitter, K. C., Wideman, G., Furey, J., Gosine, K., \& Skanes, C. (2016). Social work, gerontology, and the arts: A creative approach to teaching undergraduate social work students. LEARNing Landscapes, 10(1), $271-287$.

Strom-Gottfried, K. (2008). Values and ethics for professional social work practice. In K.M. Sowers, C.N. Dulmus, and B.W. White (Eds.), Comprehensive handbook of social work and social welfare. https://doi.org/10.1002/9780470373705.chsw001010

Taussig, M. (2011). I Swear I Saw This: Drawings in Fieldwork Notebooks, Namely My Own. University of Chicago Press.

Trevelyan, C., Crath, R., \& Chambon, A. (2014). Promoting critical reflexivity through arts-based media: A case study. British Journal of Social Work, 44(1), 7-26.

Tuhiwai Smith, L. (1999). Decolonizing Methodologies: Research and Indigenous Peoples. Zed.

Wang, Q., Coemans, S., Siegesmund, R., \& Hannes, K. (2017). Arts-based methods in socially engaged research practice: A classification framework. Art/Research International, 2(2), 5-39. 
Weiler, K. (Ed.). (2001). Feminist Engagements: Reading, Resisting, and Revisioning Male Theorists in Education and Cultural Studies. Routledge.

Zusman, A. (2018). Listen: The defeat of oppression by expression. In M. Capous-Desyllas and K. Morgaine (Eds.), Creating social change through creativity (pp. 77-93). Palgrave Macmillan, Cham.

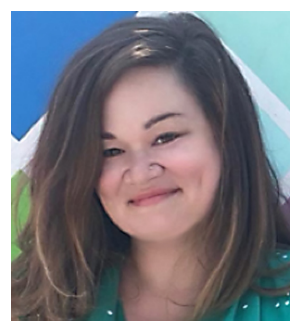

Alison L. Grittner is a PhD candidate in the Faculty of Social Work at the University of Calgary. Previously educated in Architecture, Fine Arts, and History, her transdisciplinary approach involves working alongside vulnerable communities to reimagine, codesign, and reconstruct everyday environments towards equity, empowerment, and dignity. Her award-winning praxis focuses on developing community-based knowledge of socio-spatial inequity and translating that awareness into action and intervention via the built environment. Underpinning her work is the belief that sensory and arts-based ways of knowing are a potent and untapped means of exploring emplaced experiences and raising critical consciousness.

The Social Justice Learning Collaborative comprises Alyssa Reid, Janelle Lee Pong, Jeremy Chief Calf, Jenna Hemraj, Sarah Kinnie, and Veronica Chirino Baker. 